\title{
Abstract
}

Olfaction - or smell - is one of the last challenges which multimedia and multimodal applications have to conquer. Enhancing such applications with olfactory stimuli has the potential to create a more complex - and richer - user multimedia experience, by heightening the sense of reality and diversifying user interaction modalities. Nonetheless, olfactionenhanced multimedia still remains a challenging research area. More recently, however, there have been initial signs of olfactory-enhanced applications in multimedia, with olfaction being used towards a variety of goals, including notification alerts, enhancing the sense of reality in immersive applications, and branding, to name but a few. However, as the goal of a multimedia application is to inform and/or entertain users, achieving quality olfactionenhanced multimedia applications from the users' perspective is vital to the success and continuity of these applications. Accordingly, in this paper we have focused on investigating the user perceived experience of olfaction-enhanced multimedia applications, with the aim of discovering the quality evaluation factors that are important from a user's perspective of these applications, and consequently ensure the continued advancement and success of olfactionenhanced multimedia applications.

Keywords: olfaction, multimedia, applications, virtual reality, state-of-the-art, review

\section{Olfaction-Enhanced Multimedia}

Olfaction, or smell, is one of the last challenges which multimedia applications have to conquer. As far as computerised smell is concerned, there are several difficulties to overcome, particularly those associated with the ambient nature of smell which causes interference and distortion of olfactory data when used. Nevertheless, there is a growing awareness of potential uses and benefits of olfaction in computing, and particularly in multimedia applications. To this end, we coin the term "Olfaction-enhanced multimedia applications", which we define as combining computer generated smell with other media to enrich the users' experience and perception of a multimedia presentation or application. 
In this paper, we seek to review current developments in the area of olfactory enhanced multimedia applications with a view of highlighting current research gaps, particularly those associated with user perception and experience of olfaction-enhanced multimedia applications. Accordingly, this paper starts by introducing olfaction, the human sense of smell and the psychophysics of it, which is then followed by taking a look at computerised smell and the issues surrounding its usage. Then, we review the literature relating to olfactory enhanced multimedia applications and highlight current research gaps and finally present a summary of research we have carried out in this area.

\section{Olfaction, the Sense of Smell}

Olfaction, the sense of smell, is the ability to use the nose to notice or discover the presence of an odorous substance in the air, that is, an odorant - a chemical compound that has a smell or odour. It is estimated that humans can detect 10,000 to 100,000 different odorants. We also have the capability to distinguish between slight variations in the chemical structure of some odorants, as well as being able to detect the presence of infinitesimally small amounts of certain odorants, e.g. dilutions of less than one part in several billion parts of air. Thus, while our sense of smell may not be as acute as that of other mammals, e.g. sheep dogs, bloodhounds, it is still quite sensitive and remarkably acute [83, 123].

Up until 1991, it was not understood how the recognition and perception of the 10,000 or so odours that mammals can detect actually worked and then Linda B. Buck and Richard Axel discovered the existence of a gene family in mammals which encodes olfactory receptor types and were awarded the Nobel Prize for their discovery $[25,116]$. They discovered that each of the genes in this gene family encodes a single odorant receptor type. Their research showed that the mouse, which has about a thousand of these genes, also has an equal number of olfactory receptor types. In humans, they discovered the presence of about 600 of these odorant receptor genes, with about a half of them being non-functional pseudogenes, thus leaving humans with approximately 350 olfactory receptor types. Discovering the presence of the odorant receptor genes and the role they play in odour recognition and perception of smells was the first clue in a puzzle that researchers had been trying to solve for a long while. 
Following this discovery, Buck and the rest of her research team then became preoccupied with solving the next part of the puzzle. They focused on finding out how it was possible for humans to have the ability to detect at least 10,000 different odorants with only 350 functional odorant receptor genes, and likewise for other mammals. Their research further revealed that the receptor types present in the olfactory receptor genes are used in a combinatorial manner to encode odour identities. That is, a single receptor is able to recognise multiple odorants, and a single odorant is recognised by multiple receptors, but that different odorants are recognised by different combinations of olfactory receptors. In this way, mappings of different combinations of odorant receptors create a vast array of different odour perceptions in mammals [109, 71].

\subsection{Identification and Classification of Smells}

Olfactory researchers faced the challenge of understanding how it was possible for mammals to detect and perceive so many different smells, but for ordinary humans, the problem they face daily is what to name these different smells that they are able to detect. Research $[13,21$, 39,40 ] has shown that while we are often able to detect the presence of the variety of smells we come in to contact with daily, we are often unable to associate a meaningful name to these smells and will normally identify them by saying, "this/that smell reminds me of some known object" or pointing to some object and saying, "this smells like that", that is by association $[21,39,66]$.

This difficulty in identifying and naming smells is furthermore reflected by the fact that to date there are no known standard classification schemes for smells. The most basic model of naming smells can be traced to the nature or the kind of feelings a particular smell evokes in one and the corresponding use of a synonym of 'smell'. For example, 'odour' and 'stench' are often used to describe unpleasant smells (e.g. body odour or the stench of urine); 'aroma' refers to pleasant strong smells usually from food or drink (e.g. the aroma of freshly baked bread or onions frying); 'essence' and 'fragrance' are sweet and pleasant smells such as perfumes; and 'scent' which is often used to describe natural smells or faint, barely perceptible smells such as the scent of flowers or the odour left in passing by which an animal or person 
may be traced. In literal contexts, the terms 'odour' and 'smell' are used interchangeably, however because odours are usually associated with unpleasant smells, 'smell' is the more general and neutral of these two terms, deriving connotation generally from the context in which it is used [107], or as Fox states in her article [23], 'smells are guilty until proven innocent'.

At a higher level, researchers have attempted to come up with classification schemes for identifying smells which has resulted in a number of proposed suggestions. The basis for these classification schemes varies widely, each established with different aims and objectives in mind, and differing in terms of their theoretical foundations, and as a result, comparisons between the schemes should be made cautiously [13].

In one survey of odour classification schemes, Chastrette [13] identifies that generally odour classification schemes have been derived by using one of the following approaches:

- Empirical Classifications: based on the different feelings/experience odours invoke

- Classifications Based on Primary Odours: based on a small number of reference odours

- Classifications Based on Statistical Methods: based on using multidimensional statistical methods applied to large sets of olfactory data ${ }^{1}$, including semantic descriptions of odours, odour profiles, and similarity data (ratings of similarities found between different odours).

The following were noted by Chastrette in the survey on odour classification schemes: 1) there is a weak structure of the olfactory space; 2) the dimensionality of the olfactory space appears to be rather high with no clear explanations for the nature and significance of these dimensions; 3) a hierarchical structure was never observed; and 4) the multidimensional classifications confirm that classes of odours are not clearly delineated. Nonetheless, we mention some of the more popular classification schemes below. However, further detailed information with regards to odour classification schemes can be found in [97, 13, 21, 39].

\footnotetext{
${ }^{1}$ Olfactory data as used here refers to data collected from experiments involving the olfactory sense, such as those compiled from human psychophysical studies. However, all other uses of the term, olfactory data, in this work refer to computer generated smell, i.e. smell output via devices controlled by computers.
} 
Examples of odour classification schemes based on primary odours include: the Linnaeus Classification Scheme, a 7-category classification scheme made up of the following classes of primary odours: Aromatic, Fragrant, Ambrosial (Musky), Alliaceous (Garlicky), Hircine (Goaty), Repulsive and Nauseous. In this scheme, odour classes are based on a pleasantness scale, i.e. pleasant, unpleasant \& pleasant for some and unpleasant for others $[13,39,91]$; Zwaardemaker Smell System, an extension to the Linnaeus classification scheme with the addition of two extra odour classes: Ethereal amd Empyreumatic (burnt organic matter like roasted coffee or tobacco smoke) [13, 106]; Hans Henning Smell Prism, a classification scheme which identifies the following six primary odours: Flowery, Fruity, Resinous, Spicy, Foul and Burnt, as the primary odours [13, 39, 105]; the Crocker-Henderson Smell System, an odour classification scheme, in which odours are defined by identifying the relative concentration of four primary odours: Fragrant, Acid, Burnt and Caprylic (goat-like or putid), contained in an odour on a scale of 0 (non-existent) to 8 (extreme). E.g. Acetic acid is characterised as 3803 and a Rose scent as 6423 [13, 89, 104].

Classifications based on statistical methods apply multidimensional methods to large sets of olfactory data, that is, classic semantic descriptions, descriptions emphasising similarities between odours and odour profiles featuring estimation of the intensity of each feature $[12,13$, 40]. Semantic Descriptors (also known as notes) are variables that describe chemical compounds odours possess, and in this approach, an odorous substance is described by means of a list of semantic descriptors, and the values of which can vary in intensity - that is, the approach estimates the distance between descriptors [12, 13, 40]. Examples include Dravnieks et al. (1978) and Dravnieks (1985) list of 146 semantic descriptors, with intensity variations from 0 (descriptor absent) to 5 (descriptor strongly present) [12, 40]; the 233 descriptors by Chastrette, Elmouaffek and Zakarya (1986); 126 odour descriptors by Abe et al. (1990) [13].

With odour profiles, an odorous substance is described in terms of a similarity profile that is related to a certain number of reference substances considered to represent as truly as possible the olfactory space [12]. In this approach, a test odour is compared to mentally stored templates, i.e. list of semantic descriptors, with the semantic descriptors serving to jog the 
subject's odour memory [40]. However, the problem with this approach is deciding on the choice of reference odours to base the profiling on. Nonetheless, a number of researchers have adopted this approach and simple examples include the Crocker-Henderson and Hans Henning models described above, as well as others described by Wright and Michels (1964), Amoore and Venstrom (1965), Boelens and Haring (1980), Jaubert et al. (1987) and Takagi (1987) [12, 13].

Classification schemes based on descriptions emphasising similarities between odours uses an approach where the the likeness between two odorous substances is ranked on a numerical scale fixed a priori [12]. Panels of experts are usually involved in the ranking process involving the rating of similarities between all possible odorous pairs, and the odour under investigation is compared to reference odors and the perceived similarity between the odorants is used to describe the odor. Thus, say, if an odour is perceived as being more similar to a floral odorous substance than a musky substance, it is subsequently classed as belonging to the floral group of odours [13, 40]. Researchers who have adopted this approach include Engen (1962), Schutz (1964), Yoshida (1964), Woskow (1968) Berglund et al. (1972), Dravnieks (1974) and Doving and Lange (1978), Coxon et al. (1978), Jaubert et al. (1987) and Lawless (1989) $[12,13]$.

Industry-based odour classification schemes are also quite common, and they are used to identify and describe the different classes of odours relevant to that industry. In the perfume industry, for instance, there is the Fragrance Wheel created by Michael Edwards in 1983 [118]. In the food industry, the taste of food can be altered by changing its smell, i.e. flavour, and as such a variety of flavour classification wheels to describe flavours for specific groups of consumable goods exists. Some known flavour wheels include: The Devil's Flavour Wheel, which describes bad flavours, The Beer Flavour Wheel, The Wine Flavour Wheel, The Coffee Flavour Wheel, Chocolate Aroma Wheel, Wheel of Cheese, Cornell University's Flavornet, Flavour Wheel for Maple Products [39, 93, 94, 95, 96]. 


\subsection{Individual Differences in Olfactory Perception}

In the preceding section, we discussed odour classification schemes and how they aid humans in identifying and describing the many odours we perceive. In this section, we examine individual differences in olfactory perception. Odour perception is highly subjective, has a habit of changing and it has also been found to be greatly influenced by age, sex, social and cultural factors, as well as by emotions, memory, experience and input from other sensory modalities $[13,23,31,32,34,39,40,70,74]$. In other words, the same odour may be perceived differently by separate groups of people or individuals - pleasant to some, unpleasant to another, and neither pleasant or unpleasant to others. Furthermore, an odour which may smell pleasant to an individual today, may also smell unpleasant to that same individual at a later date because of his/her current emotional state and mood and/or environmental conditions. In this section we review some of those factors known to contribute to olfactory perceptual differences amongst individuals.

\subsubsection{Age}

It has been discovered that our sense of smell is already developed to some extent when we are born, though it is thought that at the time of birth, babies are sensitive to only certain smells such as their mothers' natural odour. A number of research studies $[23,110,51,73,74$, 81] have been carried out to examine what level of olfactory development is present in infants and whether or not olfactory learning can be influenced at this early stage of one's life. These studies rely on studying the reaction, i.e. head movements, suckling behaviour and facial expressions, in infants to odours, present or absent, from their mothers breast, and - in some cases - reactions to direct exposure to specific smells [23, 74, 81].

It is thought that the human olfactory system fully develops at around the age of 8 , though there is very little evidence available to support this claim [23, 31, 123]. Other research studies suggest that our sense of smell peaks when we are in our twenties [90, 20, 23]. On the other hand, research studies $[20,35,90,22,34,39,45,121]$ have shown that the human olfactory sense declines with age and it is generally thought that this decline starts to become noticeable at about the age of seventy $[20,22,77]$. 


\subsubsection{Gender}

A number of research studies $[20,21,23]$ have shown that female test subjects generally perform better than their male counterparts in odour identification and sensitivity tests. Some research studies have also reported that this noticeable difference in sensitivity to smell between the genders is evident even in infants [74, 81], and in the elderly as well [20]. However, there are also a number of studies which report that there is no significant difference in odour detection and identification between the genders [39, 45, 79]. It is thought that a number of these studies that report on differences across the genders have not taken into consideration that odour sensitivity in females is more acute at different stages of the female cycle [23, 110, 48, 86], but there are also studies that contradict this thought [33]. Furthermore, results from some other research studies [23, 39] suggest that the difference of odour sensitivity between the genders is peculiar to certain sets of smells, rather than all smells $[23,47,48,63,122]$.

\subsubsection{Culture}

It is a well known fact that an odour that may be perceived as being pleasant to some, unpleasant to another, and to others neither pleasant nor unpleasant. Although it is generally believed that many factors contribute to the differences in odour perception amongst individuals, such as those already mentioned in this section, it is thought that culture has quite a significant amount of influence on odour perception differences in individuals. Noteworthy differences have been found between different cultural groups on their perception of intensity, familiarity, pleasantness and edibility of odours $[4,15]$. One study resulted in familiarity, pleasantness and intensity ratings being correlated in a similar way across the cultures. However, the results also revealed a separation along the pleasantness dimension between the different cultures in the case of pleasantness and intensity (which was attributed to cultural differences expressing affective judgement), while in the case of familiarity and intensity the results overlap for the different cultures [4]. In other research [14, 15], it was discovered that odour categories are based on perceptual similarities rather than on semantic cues, and odour- 
category structure might have a core representation which might be common to different cultures with boundaries which might be more culturally dependent.

Two investigative studies conducted to examine olfactory hedonic responses, which highlight interesting differences in odour perception across cultures, are mentioned by Herz in [31]. The first study was conducted in the United Kingdom in the mid-sixties, while the other was conducted in the United States in the late seventies. The striking differences between the results of these two studies highlight evidence for culturally learned odour associations. An example of one of the major differences the empirical study revealed between the populations was their perception towards methyl salicylate (wintergreen). The UK subjects gave this odour one of the lowest pleasantness ratings, while the US subjects gave it one of the highest pleasantness ratings amongst all the odours used in the study. A plausible explanation for this striking difference was subsequently attributed to the cultural history of the two populations. In the UK, the smell of wintergreen is associated with medicine, and moreover, it was widely used during World War II. While in the US, the smell of wintergreen is exclusively associated with a mint candy. Other related studies are mentioned in [24, 31, 32].

\subsubsection{Experience}

Some researchers believe that experiments involving odour perception should only use experts as subjects, because non-experts are usually a lot more subjective and emotional in their perceptions and particularly descriptions of odours identified [13]. Experts are those people who have been trained to use specific terminologies in a consistent and non-personal way in odour identification tasks. Examples of persons falling into this category may include winetasting experts and people working in perfumery.

Nonetheless, research $[64,65]$ has shown that while there might be significant differences between experts and novices when it comes to the recognition of odours, on the contrary there were no significant differences found with regards to odour sensitivity (i.e. detection and thresholds) and odour identification and naming consistency. Consequently, it was suggested that the differences associated with odour recognition are perceptual or as a result of sensory- 
based memory, rather than from having a more streamlined and concise vocabulary from which to name odours. Moreover, it has also been shown that so-called experts sometimes use subjective descriptions when identifying and naming odours [Ellena 1987 in 13], as well as the fact that they also are sometimes influenced by the presence of other cues, such as visual ones, when it comes to their judgement of odours [53].

\subsubsection{Emotions, Mood \& Memory}

Smells tend to evoke a variety of emotional feelings in humans, ranging from pleasurable feelings such as those associated with the aroma of food, scent of a mate or loved one, flowers or perfumes to feelings that may evoke disgust, fear or warn one of potential dangers, e.g. the smell of rotten food, fire, chemical dangers or the odour of an approaching intruder or predator, and even sadness from a scent reminding us of a loved one no more $[90,112]$. A good review of studies conducted to explore the influence odours have on our moods and emotions is available in [31].

One of the most reported stories that exist about the influence of smell on memory is that of Proust in his book on Things Past, of which he reports a vivid recollection from a scene in his past triggered by the aroma of a madeleine cake. Research studies conducted to explore the relationship between odour perception and memory include those reported in $[36,42,44,46]$. Findings from these studies include - olfactory memory is episodic and not semantic in nature, and while we can remember where and when we previously encountered an odour, we have difficulty recollecting the name of the odour - Herz and Eich (1995) in [42]. Olfactory memory has been found to follow a different time course than verbal memory [42, 44] - for example, most odours presented to experimental test subjects are rapidly forgotten when compared with words presented under similar conditions, but the few that are not forgotten appear to linger on in memory for a very long time. 


\section{Olfaction and Computing}

Our senses of vision and sound have dominated the computing industry since the start of the computing era. However, this is fast changing as researchers are actively seeking ways of using and combining all of the human senses in computing to enrich and to create a more interactive experience for users. To date, our senses of smell and touch continue to show greater potential for enabling a multi-sensory computing environment than our sense of taste, and significant success has already been achieved in combining and integrating smell and touch in a variety of computing systems. In this paper, our interest however lies with the former of these, i.e. smell, and we review in this section the significant developments of the use of smell in computing, as well as the potential obstacles surrounding its use.

\subsection{Olfactory Data}

The use of olfaction in computing is not without its challenges. In the case of smell as input data, the challenge is to create electronic devices that have the same capability as our noses to detect the presence of odorous substances in the air. Whilst some attempts have been made to recreate this ability electronically, the research industry is still a long way from being able to produce an electronic version of the human nose that is as sophisticated as its human counterpart. Suffice it to say, a wide variety of 'electronic noses' $[17,39,55]$ are successfully being used in industries such as the food industry for quality control and quality assurance, in the oil and gas industry to detect the presence of gas leaks and other air pollutants, and we are all familiar with the miniature version in form of smoke detectors installed in many of our homes and offices.

The current attention with smell in the computing industry, however, mostly lies with using smell as output data, where researchers are using the human ability to recognise characteristic smells to add an alternative computer output format from which conclusions may also be drawn. Kaye, in his work on symbolic olfactory displays [38, 39], distinguishes between two distinct ways in which olfactory data may be integrated and used to convey information in computing. In his work, he distinguishes between smell output to convey information where the smell released is related to the information to be conveyed and smell output to provide an 
abstract relationship with the data it expresses. Subsequently, he proposes terms to identify these two categorisations of olfactory data output and the two respective terms are:

- Olfactory Icons: which he defines as "a scent output to convey information, where the scent is environmentally and semantically related to the information to be conveyed". The idea of the term olfactory icons stemmed from the definition of the term 'icon', as well as the already well-known concept of icons as used in the computing field. Some examples of olfactory icons include emitting a lilac scent to accompany an advertisement about a perfume whose scent comes from the lilac flower, or releasing the smell of gunpowder when a shot is fired whilst playing a computer game or watching an action movie. More recently, scents have been used to as a defining element of 'decor' in hotel lobbies (checking in thus becomes a multi-sensorial experience), as well as to stimulate sales at point of purchase [113].

- Olfactory Smicons: defined by Kaye as "scent used to convey information that has only an abstract relationship with the data it expresses". For example, setting up a notification alarm using olfactory data alarms e.g. the smell of your favourite dish to notify you that it is lunch time or the smell of your loved one's perfume to notify you that it is closing time.

As mentioned above, olfactory data is virtual in nature, and for this reason it has to be stored in an external peripheral device attached to a computer with its emission generated by triggering the devices' output stream from the computer it is attached to. To this end, a variety of computer-controlled olfactory devices have been implemented to transfer smell output information, i.e. olfactory data, to users at the receiving end. However, although prototypical designs have been created for a lot of these devices, very few of them have ever been made commercially available. Some of of these devices relating to olfaction-enhanced multimedia research are listed below:

- ScentWave by ScentAir [www.scentair.com]

- ScentController by ScentCommunication [www.scentcommunication.com]

- iSmell by DigiScent [29, 30, 119]

- ScentDome by Trisenx [www.trisenx.com]

- Vortex Active by Dale Air [www.daleair.com] 
- Exhalia [www.exhalia.com]

- Scent Collar [80, 85, 98, 103]

- The D.I.V.E Fire-fighter Training System [39, 85]

- Projection-Based Olfactory Display with Nose Tracking [56, 85, 87, 88]

- Odor Recorder [60, 61]

- Kaye, in his work on symbolic olfactory devices [39], also experimented with a few prototypical designs of olfactory data display devices.

\subsection{Olfactory Data Issues in Computing}

To date, there is still a rather limited use of olfaction in computing, as well as a relative paucity of research in this area, and is an indication of how challenging research and industry are finding olfactory data. These challenges may be attributed to two main reasons; firstly, the lack of suitable devices that are sophisticated enough to meet the demands of today's advanced technology world, and secondly the challenges introduced from the characteristic nature of smell. Our interest in this paper, however, lies with the latter of these, and forms the basis of the remainder of our discussion on olfactory-enhanced multimedia. Moreover, challenges faced with the lack of suitable olfactory generating devices have already been presented in this paper in the preceding section.

\subsubsection{The Characteristic Nature of the Sense of Smell}

According to Köster [42], the sense of smell is a nominal sense, that is, it is only able to provide us with simple, nominal information about the presence of qualitatively different odorous substances in our surroundings. That is, although our sense of smell is extremely sensitive and has the ability to distinguish between many different odours, the human sense of smell has poor odour intensity discrimination. Thus, making it difficult for humans to detect differences in odour concentrations unless the differences are about magnitudes of $20 \%$ or higher. The sense of smell is also a near sense, in which case it tends to be passive until a stimulus arrives to activate it, and even then we rely mostly on our sense of vision to find its source. This is as a result of all information about the quality of an odorous substance is 
contained in the molecules that make direct contact with the olfactory receptors. However, one major problem of the olfactory sense being a near sense and often relying on our sense of vision to find its source is that potentially what we see may influence our perception of the odours we perceive. A number of research studies $[6,69,76]$ have shown that this is indeed mostly the case.

Furthermore, the sense of smell is, according to Köster [42], a hidden sense, in that olfaction is seldom the focus of attention, with the consequence that awareness of odours is the exception rather than the rule. Whilst the olfactory sense is one of the major human senses and olfactory stimui are omni-present in everyday life, this tendency of olfaction to 'hide' itself, as Köster puts it, is further reflected in odour adaptation and odour habituation. The former is experienced when we lose our sensitivity to detect smells after continuous exposure and prolonged stimulation of the olfactory sense. For example, if long enough intervals are not introduced between odours presented in odour identification experiments involving a number of odours, say, subjects taking part are likely to soon reach a state of odour adaptation where they are no longer able to distinguish between, and possibly even detect and respond to, the successive odours they are presented with. On the other hand, we experience odour habituation when continuously exposed to the same odour repeatedly, thus our attention and responsiveness to this particular odour becomes reduced. Nevertheless, when olfactory stimuli can no longer be perceived or are no longer attended to as a result of adaptation or habituation, they still continue to exert influences on our behaviour and mood. The suppression of odour intensities when mixed odours are perceived is another way in which olfaction shows the tendency to hide itself

Köster also remarks that the sense of smell is an associative and emotional sense [42]. Generally, odours are linked to emotions by association, where most of those links are created without any intention to learn and result simply from contingent circumstances where the subject may not even be aware of the odour's presence. However, it is these individual emotional links that we associate with odours that are largely responsible for the great level of subjectivity associated with odour perception. Lastly, the sense of smell has a special memory [42]. That is, it is episodic and not semantic in nature, and while we often can remember 
where and when we encountered an odour previously, even after long periods of time, in most cases we cannot recall the name of the odour, and if we do, it is often by deduction.

As a result of these issues relating to the characteristic nature of smell, certain measures need to be taken into consideration to ensure the successful use of olfactory data. Kaye, in his work on olfactory symbolic displays [39], suggests that "olfactory display must primarily rely on distinctions between different odours, rather than differences in the intensity of the same aroma". Köster, on the other hand, suggests that the detection, discrimination and recognition of odours as being familiar or unfamiliar are more important than assessments of intensity gradients or verbal identification of the odour. Moreover, long enough intervals must be introduced between successive odour displays used in applications, experiments etc., Lastly, research studies that rely on human discriminations of odours must be large enough to eliminate possible discrepancies that may arise as a result of odour perception variability amongst subjects. An alternate approach is to use olfactory data from those set of smells that we have all, or at least most subjects, been conditioned to learn over time, that is, smells that are likely to be familiar across participants regardless of age, gender or culture.

\subsubsection{The Characteristic Nature of Smells}

In addition to the issues surrounding these characteristics of the olfactory sense, there are also issues associated with smells, that is, the odorous substances that we perceive with our olfactory sense and these are discussed below.

\subsubsection{Smells Drift and Diffuse}

Odour perception is highly dependent on the molecular mobility of odorous substances to reach our olfactory receptors for detection. However, the molecular mobility of odours and their volatile nature means that odours are highly susceptible to present atmospheric conditions, which may be direct from Mother Nature or artificially created. The influence of atmospheric conditions, which can also be highly unpredictable at times, means that during the course of transmission of odours to olfactory receptors within range there is often limited 
control over the direction and the speed at which odours travel. The consequence of this is that odours tend to drift and/or diffuse when released into the atmosphere. Therefore, research studies or systems requiring sensory analysis or interpretation of olfactory data generated by olfactory data display devices, as opposed to the subjects or users directly sniffing the smells, need to be controlled in some way. This is because the atmospheric conditions present may cause the olfactory data to drift off in the wrong direction and miss the intended target, take a while to reach the target, or it might also be the case that the atmospheric conditions are not even volatile enough to carry the smells within range of the users' nasal passage for their olfactory receptors to detect them.

It is for this reason that designers of olfactory data display devices have tried to invent a number of ways to control the flow of olfactory data to ensure that it reaches the intended target. The methods employed generally fall into two categories, namely devices that include some form of control over the diffusion of the emitted odour alone, i.e. preventing it from spreading out in many directions; and devices that ensure that the odour is distributed within range of the intended subjects' nasal passage, as well as including some form of control over the diffusion of odours. The devices in the latter category often require the user to wear some part of the device to ensure that the smell is emitted within range of the nose and there are others that use a tracking device to locate the target users' nose and then project the odours within range of his/her nose $[56,87,88]$. The disadvantages of these approaches however is that wearable devices can be an encumbrance for the user and the emitted scent can cause a choking effect or allergic reaction in the case of the odour being directly transmitted within a very short distance of the users' nose. Moreover, the aim of adding olfactory data to computing applications such as virtual reality applications and training systems is to simulate real or imagined conditions, and in such scenarios the experienced sensation of the olfactory data should be as natural as possible. For instance, in $[87,88]$, the researchers discovered that with their original scent projector users experienced an unnatural airflow when the scent was emitted. Consequently, they improved on their original design in [56]. Thus, devices that emit olfactory data as whiffs of scents are better suited for such purposes. 


\subsubsection{Smells Linger}

Smells, when released into the air, have a tendency to linger on in the atmosphere. This lingering nature of smells may be as a result of stifling atmospheric conditions or the pungency of the smells emitted. The effects of lingering smells in the air, and particularly in research studies and computing studies is that they may interfere with the detection and perception of subsequent odours released, if applicable, and may also cause headaches, nausea and other uncomfortable feelings in users.

In the case of interference with odour detection and odour perception, the lingering effect of smells may subsequently result in the experience of olfactory adaptation, olfactory habituation and mixture suppression $[11,16,42,78]$. To circumvent these issues, appropriate intervals should be introduced between odours released in succession or odour neutralisers may be used to suppress the previously emitted odour(s), and the smells should also not be emitted for continuous long periods. In [84] it is reported that some studies have suggested that two odours emitted in sequence must be separated by at least 20 to 60 seconds in order to be clearly perceived and moreover, the average time it takes to sniff a scent typically ranges from $0.5 \mathrm{~s}$ to $2.5 \mathrm{~s}[24,43]$. In addition, odour concentrations should be kept to a minimum, and fans or similar devices may be used to circulate the air or windows, or other ventilation systems, opened or activated to ventilate the air.

In this section, we have discussed some of the issues faced when olfactory data is used and it is clear that there are still a number of difficult challenges facing the research industry with regards to the use of olfactory data. Nonetheless, there are several benefits to be gained from the introduction of olfactory data in computing systems and applications and there have been significant developments in respect of its usage. In the following section, we discuss the use of olfactory data in the multimedia applications.

\section{Olfaction-Enhanced Multimedia}

Olfaction-enhanced multimedia applications combine computer generated smell with other media to enrich the users' experience and perception of a multimedia application. Combining 
artificially generated scent with other media content in order to enhance the meaning of userpresented information can be traced back to the $20^{\text {th }}$ century. Although, the idea was not found widely acceptable or particularly appealing to users back then, these earlier attempts at creating olfaction-enhanced audiovisual presentations provide enlightening and interesting background into this research area.

The downfall of these earlier attempts may largely be attributed to the technology used, or to be more exact, the lack of appropriate technology to emit scheduled scents and in controlled amounts. Nonetheless, several years later with great advancements in technology, olfactionenhanced multimedia is still a challenging research area. Consequently, even the more recent attempts at creating olfaction-enhanced multimedia systems and displays have faced challenges of their own, with the result being that progress is still nowhere near as advanced as one would expect. In this section, we summarise some of the more significant developments of olfactory-enhanced multimedia over the years.

\subsection{Scented Media in the Film Industry}

The first recorded attempt of combining artificially generated smell with audiovisual content dates back to 1906 when an audience was sprayed with the scent of roses while watching the screening of the Rose Bowl football game [Longino in 39], however, there is no mention of what the audience reaction to this was. The next significant development in the use of scented media in the film industry happened in 1943 [111, 120], when Hans Laube, who had earlier discovered a technique for removing odours from an enclosed place, such as an auditorium, was also able to reverse this process to release selected odours into similar places at specific times and durations. Using his newly discovered technology, and with the help of his colleague, Robert Barth, they produced a 35 minute 'smell-o-drama' movie called Mein Traum in which 35 different odours were released to accompany the drama presentation. However, the technology behind the production of the emitted smells enjoyed more success than the scented drama presentation itself, with the audience agreeing that while the smells emitted were promptly released and subsequently removed, they smelled fake. Nonetheless, it 
was the success of Laube's technology for emitting smells that Michael Todd Jr was to rely on later in 1960 in his Smell-O-Vision Scent of Mystery film production [111, 120].

In 1959, a year before the release of the aforementioned Michael Todd Jr's Smell-O-Vision Scent of Mystery film production, there was the AromaRama presentation, a documentary about Red China called Behind the Great Wall [39, 111, 82, 100]. Smells were emitted via the theatre's air-conditioning system to accompany the presentation of this documentary. Unfortunately, the producers had no way of knowing what a significant impact the characteristic nature of smell would have on their presentation, and they went all-out and had over 30 different smells released during the presentation. The reaction of the audience to this presentation varied from complaints that the smells were phoney, too pungent and not always removed as rapidly as the scene requires [39].

In the year following the AromaRama presentation, and hot on the heels of Laube's success with the technology used in the 'smell-o-drama' movie of 1943, there was another attempt at creating scented media for the film industry in a film production called Scent of Mystery [39, $82,111,120]$. This film production was a murder mystery in which scents were synchronised with certain scenes of the film in order to aid in revealing the identity of the murderer. This time, the producers had done more research into the matter and of course had the added advantage of being able to refer to the AromaRama experience and of using technology that had proved reliable when it came to promptly releasing and subsequently removing smells. Thus, they went ahead and also released as many as 30 smells during the film, as after all, the technology had proven that it could cope with this $[111,120]$. Unfortunately, despite the better preparation and the better technology, this scented media production also fared badly [39, 82 , $100,111,120$,$] and the Smell-O-Vision Scent of Mystery drama continues to live in infamy to$ date $[111,120]$.

After these well publicised failures with the use of smell in the film industry, the production of scented films disappeared for a while, and though there have been a few more attempts to create scented media experiences for users since then [39, 102, 108, 117], the idea has still not quite caught on to date. One example of these later attempts is John Waters' 1981 scented 
movie, Polyester [39]. Waters created what he called Odorama cards, which were basically scratch ' $\mathrm{n}$ ' sniff cards, similar to those used in advertising perfumes in magazines. Subsequently, members of the audience were each provided with 10 numbered Odorama cards prior to viewing the movie, and when a number flashed on the screen, viewers were to scratch and sniff the corresponding card. The Odorama cards used featured a mix of both pleasant and unpleasant smells, and included the scent of flowers, pizza, glue, gas, grass, and faeces.

\subsection{Scented Media in Computing}

The predominant cause of these failed attempts at creating notable scented film experiences for users was the failure of the technology. Hence, with computing technology already well underway by the 70s, and enjoying considerable success, research started to look at ways of using computing technology to control the emission of scents in order to create an olfactionenhanced experience for users. Unfortunately, despite the newer technology, progress is still not what one would expect for the current level of technological advancements.

The relative scarcity of commercially available olfactory data generating devices has certainly contributed to the slow progress of the use of olfaction in computing. However, a further hindrance stems from the fact that whilst it is usually easy to combine other data formats (e.g. sound and video) to produce a desired output mix, this is extremely difficult to do with olfactory data as a standard additive process or model for combining different scents does not exist. Consequently, more often than not smell generating devices are limited to producing the specific smells that have been loaded into their respective storage systems.

Nonetheless, there has been some olfactory data usage in the computing field over the years, with a number of researchers building their own computer generating smell systems [8, 39] and others relying on the few that are commercially available. More recently, Nakamoto and his team [57 - 61] have developed a smell generating device which works by combining chemicals to produce the desired scents as and when required. In the researchers' earlier work, an olfactory display device with 32 odor components using solenoid valves was created [58]. They also produced what they call an odor recorder in [60,61], and this device is capable of determining the qualitative and quantitative composition of target smells, as well as 
reproducing these 'recorded smells' when required later on. In their more recent work [57], the researchers seek to extend the capability of their original olfactory display device and study a method of selecting odor components using a large-scale mass spectrum database of 104 odors composed of 322 compounds. Their work addresses one of the major challenges of olfactory data display devices. That is, the capability of providing a diverse range of smells, i.e. olfactory data, to use with the device as and when applicable. Existing olfactory display devices tend to come with a limited number of olfactory data storage units, with each unit capable of being preloaded with only one smell at a time.

The areas of computing that have experienced significant usage of olfactory data over the years include virtual reality, multimodal displays and alerting systems, and media and entertainment systems. Olfactory-enhanced multimedia research efforts in these areas are discussed below.

\subsubsection{Olfaction and Virtual Reality}

In 1962, Morton Heilig created what is now popularly dubbed as the first virtual reality (VR) experience for users, even though digital computing and virtual reality systems did not exist then $[18,39,99,101]$. He created Sensorama, an arcade-style device, which took users on an immersive 3-D virtual reality bike ride experience through the streets of Brooklyn. Using motion and vibrations, sounds, fans and smells, Sensorama created a multi-sensory experience for users which simulated those sensations one is likely to experience on a motorbike ride through the streets of Brooklyn. These sensations included the bumpy feeling a rider may experience as he/she travels over cobblestones, as well as the sights, sounds and smells (the aroma of freshly baked bread from the bakery, scents of hibiscus and jasmine from the flower gardens passed) that may be experienced as the rider continues on his journey.

Although VR systems are quite popular today, most still fall short of providing the kind of multi-sensory experience that Heilig's mechanical device did [18], as most of these systems still only engage our visual and audio senses, with a few more our tactile sense. Indeed, olfaction is still something of a rarity in these systems. One of the most notable virtual reality 
systems involving the use of olfaction reported since Heilig's invention is the fire-fighter virtual reality training system designed by Cater and his team in 1992 [18, 39]. Here, the user wears a backpack mounted device, which emits a range of scents, including burning wood, grease and rubber, sulphur, oil and diesel exhaust, through an oxygen mask connected to the device, whilst immersed in the virtual reality environment. The essence in this case is to familiarise potential fire-fighters with those smells often associated with fires, as it is often thought and argued that it is easier to recognise smells already known by a person. Moreover, in a fire-fighter's profession, being able to easily detect the presence of such smells could well prove to be invaluable. Notable feedback from Cater's virtual reality training system, and another worthy contribution to the guidelines on the use of olfactory data, was that one has to be careful with the intensity of smells used in any experiments involving the use of olfactory data as users can suffer a variety of reactions from smells, ranging from headaches to allergic reactions and being physically sick.

In [18], Dinh et al report on an experimental study carried out which investigated the use of tactile, olfactory, and auditory sensory modalities with different levels of visual information on a user's sense of presence and on the user's memory of details of the virtual experience. Their study involved participants evaluating a virtual corporate office suite environment system that could also be potentially used by real estate brokers to show prospective tenants available properties. The olfactory cue used was the scent of coffee as the participant entered the reception area containing a coffee maker machine. The findings from their study showed that additional sensory input can increase both the sense of presence in a virtual environment and memory for the objects in the environment, with the sense of presence increased mostly by the addition of tactile and auditory cues. Olfactory cues produced a non-significant trend in the case of the effect on the sense of presence, but a significant main effect on memory.

Another reported study that investigated the use of olfaction in virtual reality environments was the study carried out by the Research in Augmented \& Virtual Environment Systems (RAVES) project team at the Institute of Simulation \& Training, University of Central Florida [37]. The focus of this study was to test the impact of olfaction on a human operator's sense of immersion into a virtual environment. The experimental study involved participants playing a 
computer game in an immersive virtual experiment. The experimental conditions consisted of a control case where no scents were released whilst the participant played the game and two experimental cases, one involving concordant scents (i.e. emission of the scent of ocean mist as the player passed the ocean and a musty scent when the player was in the fort in the immersive environment) and the other a discordant scent (smell of maple syrup throughout the game). The results from their study showed that the addition of an olfactory component did not significantly enhance immersion into a simulated environment.

Spencer [75] recognises the need for the inclusion of olfactory data in Patient simulators, which are being used to aid the training of medical personnel. Some illnesses, such as diabetes and schizophrenia, have characteristic smells associated with them, whilst with some other illnesses patients are known to experience certain olfactory deficits and dysfunctions [23, 39, $75,110]$. In the former case, virtual reality training systems may be designed to help young doctors to recognise such odours and subsequently aid them in diagnosing cases. In fact, Krueger in [18] suggests that surgical training systems, potentially one of the most important developing applications of VR, will be incomplete unless odours are present.

\subsubsection{Olfaction in Multimodal displays and alerting systems}

Benefits of multi-modal systems include synergy, redundancy and an increased bandwidth of information transfer [72]. Most of the developments involving the use of olfactory data in multi-modal systems have, however, been where the addition of another modality has been used to provide redundancy, i.e. the use of several alternative modalities for processing and/or presenting the same information to users. One benefit of having such multi-modal information displays is to share attention and information processing demands between our different senses. As it is, our visual and auditory senses are already overburdened with the respective visual and auditory cues we are required to respond to in computer information systems. Thus applications used to gain the users attention, more popularly known as notification or alerting systems, represent one of the areas in which olfactory data output has been found quite beneficial. 
To support his theories on symbolic olfactory displays, Kaye [39] designed a number of notification and alerting prototypical applications that made use of olfactory data alarms. These include 'inStink', a simple application he built to demonstrate the viability of computergenerated smell. Its mode of operation was simple - when a particular spice was used from a spice rack, the corresponding smell of the spice was released by the simple olfactory device. Next came 'Scents and Dollars', an application that used computer-generated smells to notify observers of when the stock market went up or down; 'Smell Reminder', which allows users to use what he calls smicons (described in section 2.1) to create personal, notification alarms, and 'Honey, I'm home', an application shared between two people which ensures that out of sight, is not out of mind and where smicons are used to alert the other that you are thinking of him/her.

Bodnar, Corbett and Nekrasovski [7] also created a notification system that makes use of olfactory data. In their work, they conducted an experimental study to compare the effect the use of visual, audio or olfactory displays to deliver notifications had on a user's engagement of a cognitive task. Participants were given an arithmetic task to complete and at various intervals two types of notifications were triggered, one where the participants had to immediately stop what they were doing and record some data before returning to the completion of their task, and the other they were to ignore. With their experiment, they found that while olfactory notifications were the least effective in delivering notifications to end users, they had the advantage of producing the least disruptive effect on a user's engagement of a task.

In the realm of multi-modal information processing, we mention the study carried out by Brewster, McGookin and Miller [9]. Here, they use olfactory data for multimedia content searching, browsing and retrieval, more specifically to aid in the search of digital photo collections. In their experiment, they compare the effects of using text-based tagging and smell-based tagging of digital photos by users to search and retrieve photos from a digital library. To achieve this, they developed an olfactory photo browsing and searching tool, which they called Olfoto. Smell and text tags from participants' description of photos (personal photographs of participants were used) were created and participants had to use these tags to 
put a tag on their photos. At a later date, participants then had to use the same tags to search and answer questions about the previously tagged photographs. The results of their experiment showed that although performance with the text-based tags was better, smell and its ability to trigger memories in individuals does have some potential for being used as a querying method for multimedia content searching.

\subsubsection{Olfaction in Multimedia entertainment systems}

Multimedia entertainment, such as computer games, is another area that is expected to benefit greatly from the addition of our other sensory cues which are currently virtually non-existent in such applications. It is expected that they will heighten the sense of presence and reality and hence impact positively on user experience, e.g. make it a more engaging experience for users.

Fragra, [92, 52] a Visual-Olfactory virtual reality game that enables players to explore the interactive relationship between olfaction and vision, is one such application. The objective of the game is for the player to identify if the visual cues experienced correspond to the olfactory ones simultaneously. A similar interactive computer game, 'Cooking Game', has also been created by Nakamoto and his research team at the Tokyo Institute of Technology [58, 114, 115].

More recently, Boyd Davis et al. [8] used olfactory data to create an interactive digital olfactory game. However, the main aim of their experiment, what should the designer of interactive systems know about olfactory data, is a question already answered by predecessors in the field such as $[7,9,39]$. In their work, they developed a suite of digital games in which they use olfactory data, 3 different scents, to engage users in game play and the users' sense of smell is the main skill needed to win the games. The findings from their work further confirm what previous researchers like Kaye [39] have discovered about the use of olfactory data and set down guidelines for.

In [41], an olfactory display system called "FragrantMemories" was designed, which will enable users to easily create fragranced home movies. Using their "FragrantMemories" system, the researchers conducted an evaluation experiment to verify the need for olfaction- 
enhanced broadcasting in TV. The results of their evaluation experiment verified that there is an increasing demand for TV broadcasting to include the transmission of olfactory data signals. Similar olfaction-enhanced display systems have also been implemented in [49, 50, 67]. The former, $[49,50]$, focuses on the technical aspects of olfaction-enhanced displays and proposes to use computational fluid dynamics (CFD) to calculate odour distribution and subsequently use an odor blender [58] to generate the odor with the concentration determined by the calculations. In the latter example [67], a simple olfaction-enhanced multimedia display system is implemented, which the researchers' use to investigate the usability and efficiency of their system.

In summary, much of the olfactory-enhanced multimedia research studies have focused on whether computer generated scent can be successfully output to aid perceptual displays. However, there are still a number of challenges to be addressed, steming from both the use of olfactory data itself as well as the added difficulty of integrating it with other media objects. As a consequence, there are notable gaps in the research field and we summarise in Figure 1 what we believe are the main challenges facing olfaction-enhanced multimedia applications.

Of these challenges, the issue of smell generating devices is a hardware issue. There are already significant developments in this area (see section 2.1). Issues relating to smell quality, i.e. how many smells, and smell quantity, i.e. what concentrations of smells, do not strictly represent a multimedia problem and have also been addressed in previous research work [1, 5, $39,54,78]$. Therefore, the other two of these challenges highlighted in the chart, i.e. content association and synchronisation, are the notable, current research gaps relating to olfactoryenhanced multimedia. 


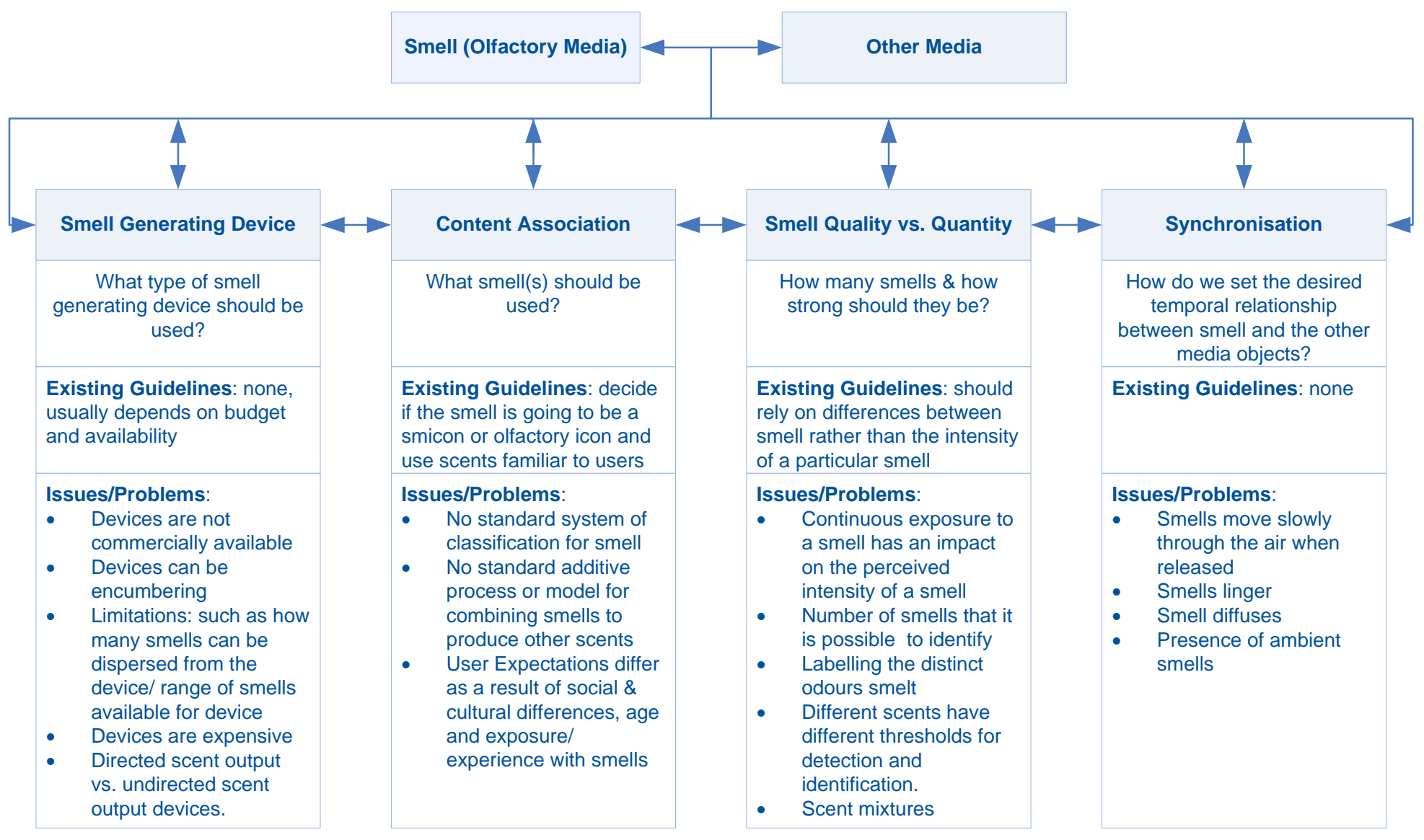

Figure 1: Challenges facing the integration of olfactory media with other media in multimedia applications 
Furthermore, our review of the current literature relating to olfactory-enhanced multimedia has revealed that what little research exists has focused mainly on technical issues. That is, making olfaction work with other media, with the majority of these studies not reporting of any detailed evaluation of these applications from the end users' perspective. As such, the ever so important user-perceived experience has been neglected. Thus, it is not yet understood what quality evaluation factors are important from the end users' perspective for this type of multimedia application. As multimedia applications are inherently user-focused, the lack of research relating to the user-perceived quality of experience of olfaction-enhanced multimedia applications is an important research gap in this domain that needs to be filled. In view of this, and the two research gap areas highlighted above, in the following section we present what we consider to be directions for future research in the area of olfactory-enhanced multimedia, with particular emphasis on the user-perceived experience.

\section{Directions for Future Work}

Multimedia lies on an infotainment continuum, using multiple forms of media information content to inform and entertain users. Content association and synchronisation are at the fundamental core of achieving quality multimedia, and as a result both of these issues are also concerned with the infotainment duality nature of multimedia. Accordingly, to consider the end of the multimedia continuum which seeks to inform the user, we expand the research gap domain to include the influence of olfaction on task related challenges in multimedia applications. Also, at the other end of the continuum - focusing on user entertainment - the user-perceived level of enjoyment of olfaction-enhanced multimedia needs to be considered. In this light, we put forward the following as possible directions for future work in respect of exploring the user-perceived quality of experience of olfaction-enhanced multimedia (see RQ1 to RQ4b in Figure 2):

- Empirical exploration of the impact on user experience and enjoyment of augmenting multimedia content with olfaction. does augmenting multimedia applications with olfaction enhance the user experience of multimedia? (RQ1)

- Empirical exploration of the acceptable user temporal boundaries within which scents can be emitted in olfactory-enhanced multimedia. what are the temporal 
boundaries within which scents can be emitted so as not to adversely affect the user experience? (RQ2)

- Empirical exploration of user perception of the association between olfactory media content combined with other media content in olfactory-enhanced multimedia. does the association of scent and content enhance the user experience of multimedia applications? (RQ3)

- Empirical exploration of the influence of olfaction on information recall in multimedia applications. does olfaction enhance user information recall in multimedia applications? (RQ4a)

- Empirical exploration of the effect of introducing an information recall task on user enjoyment of olfaction-enhanced multimedia applications. how is user enjoyment of olfactory-enhanced multimedia applications affected by the introduction of an information recall task? (RQ4b)

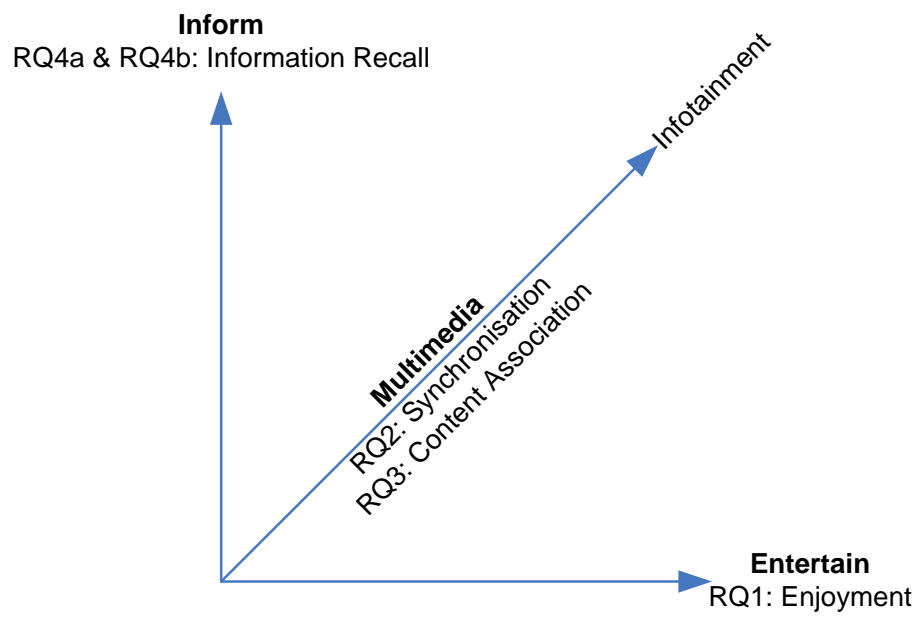

Figure 2: The infotainment continuum of multimedia, depicting where possible research questions (RQ) lie.

\section{Olfaction-Enhanced Multimedia: Our Research}

We have conducted some preliminary investigative studies relating to the proposed directions for future work and possible research questions raised above. Our research has focused on investigating the user-perceived experience of olfactory-enhanced multimedia applications and 
findings from some of our research studies have been published elsewhere in $[1,2]$. Generally, our research findings are quite encouraging as they reveal positive user attitude towards olfactory-enhanced multimedia and also, that users enjoy an enhanced multimedia experience when augmented by olfactory stimuli. Moreover, users do attach semantic meaning to the olfactory media, with the consequence that its presence is perceived as much more than a gimmick that would be diminished in time.

Table 1

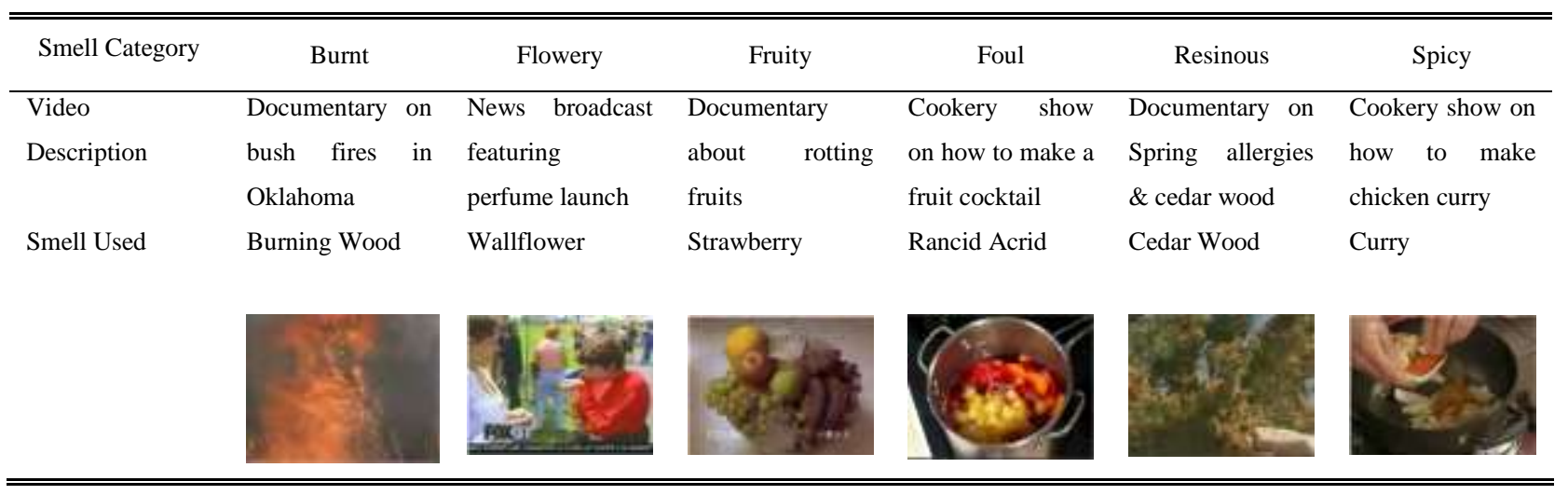

For our research, we designed a multimedia presentation display program, which displays visual and audio media content from video clips synchronized with olfactory data (described in Table 1). The smell generating device we have used in our experimental studies is the Vortex Active scent dispensing system by Dale Air (shown in Figure 3). It is a personal computer smell dispensing system which uses miniature fans to propel the emitted smells in the right direction and it connects to the computer via a USB port. The device is supplied with a USB fan controller API that is used to manage the release of olfactory data. We have integrated this API with our multimedia presentation display program to control the synchronized release of olfactory data during each video playback. The smells used in our research have been selected from the six smell categories, Burnt, Flowery, Fruity, Foul, Resinous and Spicy, described by Hans Henning [13, 39, 105]. 


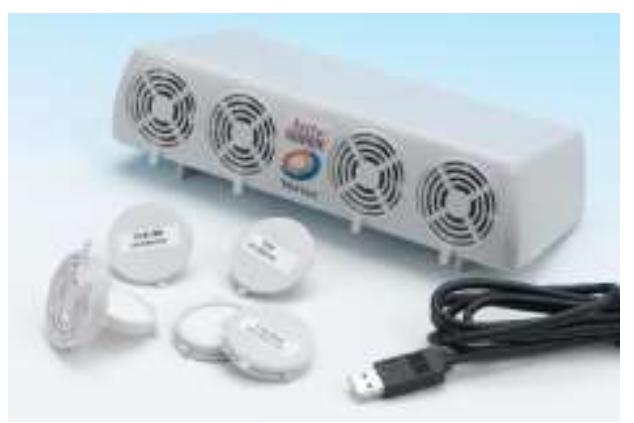

Figure 3: Vortex Active from http://www.daleair.com/acatalog/Dispensers.html

Based on our preliminary findings, as well as our review of olfaction-enhanced multimedia research, we have put forward a few user-centred design guidelines for the integration of olfaction in multimedia applications. The proposed guidelines have incorporated the work of Kaye [39], whose pioneering efforts have played a significant role in creating an awareness of the issues, problems and limitations associated with the use of olfactory data. Furthermore, our proposed guidelines have been divided according to the two levels at which the users' perspective of multimedia quality can be measured and adjusted, as defined in [27, 28]. Accordingly, the guidelines include factors affecting the media and content levels. We summarise these guidelines in form of a model, which we present in Figure 4.

\section{Conclusion}

In this paper, we have introduced the user to the concept of olfaction-enhanced multimedia applications and the issues concerning the progress of such applications in the multimedia field. We have identified the specific research gaps relating to olfactory-enhanced multimedia applications and subsequently suggested possible directions for future work. Furthermore, we have also proposed a set of user-centred design guidelines for the integration of olfaction in multimedia applications.

In conclusion, olfaction is one of the last barriers that multimedia applications have to overcome in order to truly engage a person's complete sensorial array. Problems in practice range from lack of standardised categorisation schemes making it difficult to associate smells with content that is suited to all levels of users in a meaningful way, to possible 
synchronisation problems as a result of the nature of smells to drift, diffuse and linger on when emitted. Our preliminary research has presented evidence, though, showing that users are prepared to overlook these drawbacks of olfactory media, and that there is generally an across the board positive bias towards the use of olfaction in multimedia applications. 


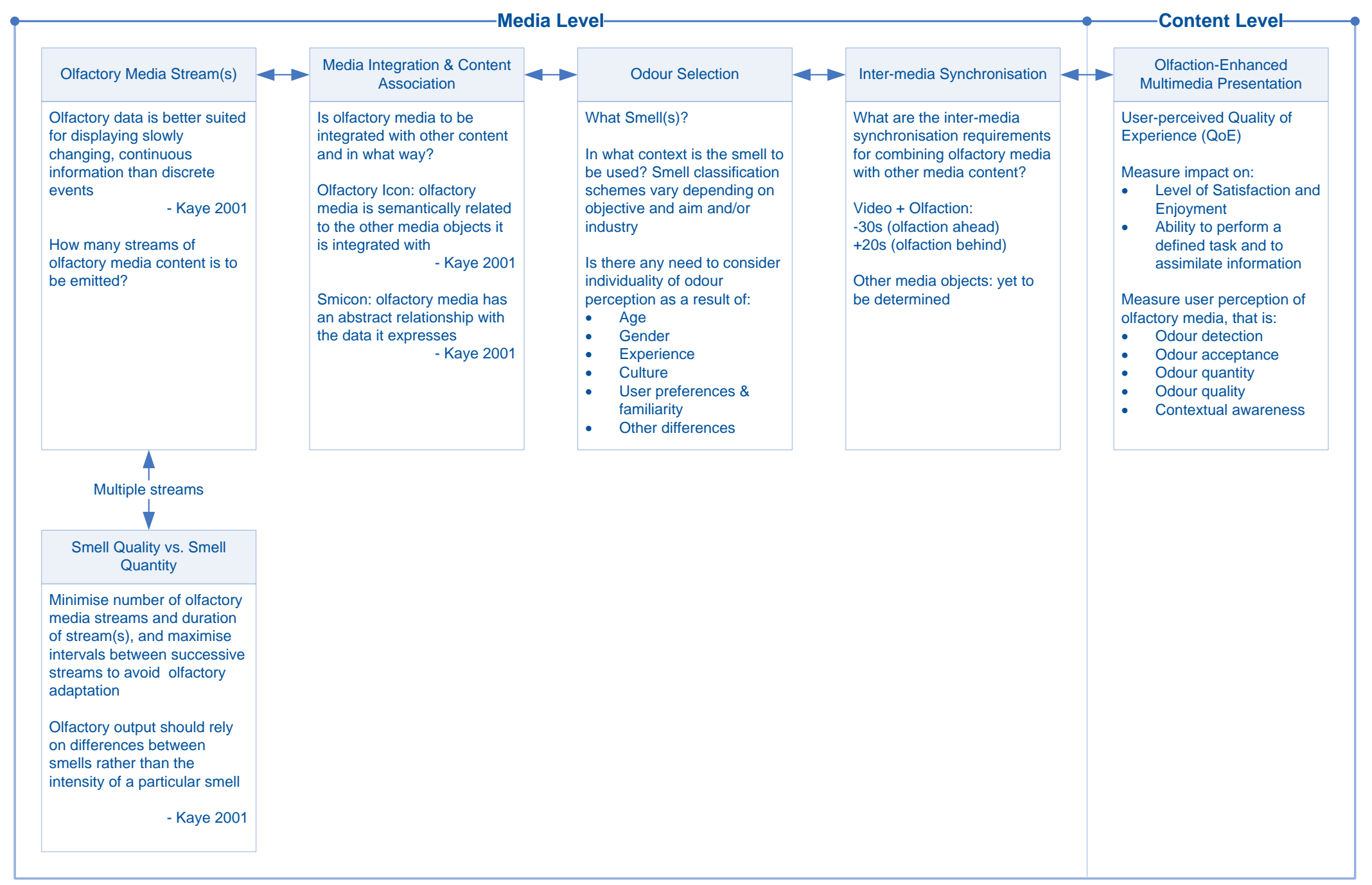

\section{Figure 4 Guidelines for achieving quality olfaction-enhanced multimedia from the user perspective}




\section{References}

1. Ademoye, O.A. \& Ghinea, G. 2007, "Olfactory enhanced multimedia applications: perspectives from an empirical study", MMCN'07 - Fourteenth Annual Multimedia Computing and Networking Conference, vol. 6504, pp. 65040A-65040A-9, San Jose, California.

2. Ademoye, O.A. \& Ghinea, G. 2008, "Synchronisation of olfactory-enhanced multimedia: Perspectives from an empirical study", ICME 2008 - IEEE International Conference on Multimedia and Expo, pp. 1425-1428, Hannover, Germany.

3. Atanasova, B., Langlois, D., Nicklaus, S., Chabanet, C. \& Etiévant, P. 2004, "Evaluation of olfactory intensity: Comparative study of two methods", Journal of Sensory Studies, vol. 19 , no. 4 , pp. 307-326.

4. Ayabe-Kanamura, S., Saito, S., Distel, H., Martínez-Gómez, M. \& Hudson, R. 1998, "Differences and similarities in the perception of everyday odors. A Japanese-German cross-cultural study", Annals of the New York Academy of Sciences, vol. 855, pp. 694-700.

5. Berglund, B., Berglund, U. \& Lindvall, T. 1986, "Theory and methods for odor evaluation", Experientia, vol. 42, no. 3, pp. 280-287.

6. Blackwell, L. 1995, "Visual cues and their effects on odour assessment", Nutrition \& Food Science, vol. 95, no. 5, pp. 24-28.

7. Bodnar, A., Corbett, R. \& Nekrasovski, D. 2004, "AROMA: Ambient awareness through olfaction in a messaging application: Does olfactory notification make 'scents'?", ICMI'04 - Sixth International Conference on Multimodal Interfaces, pp. 183.

8. Boyd Davis, S., Davies, G., Haddad, R. and Lai, M. 2006. "Smell Me: Engaging with an Interactive Olfactory Game", Proceedings of the Human Factors and Ergonomics Society 25th Annual Meeting, pp. 25-40, UK.

9. Brewster, S.A., McGookin, D.K. \& Miller, C.A. 2006, "Olfoto: Designing a smell-based interaction", CHI 2006: Conference on Human Factors in Computing Systems, pp. 653.

10. Buck, L.B. 1999, Researchers Discover How Mammals Distinguish Different Odors, Howard Hughes Medical Institute (HHMI). Available: http://www.hhmi.org/news/buck.html [Accessed: September 21, 2007]. 
11. Cain, W.S. \& Polak, E.H. 1992, "Olfactory adaptation as an aspect of odor similarity", Chemical Senses, vol. 17, no. 5, pp. 481-491.

12. Callegari, P., Rouault, J. \& Laffort, P. 1997, "Olfactory quality: From descriptor profiles to similarities", Chemical Senses, vol. 22, no. 1, pp. 1-8.

13. Chastrette, M. 2002, "Classification of Odors and Structure-Odor Relationships" in Olfaction, Taste, and Cognition, eds. C. Rouby, B. Schaal, D. Dubois, R. Gervais \& A. Holley, Paperback Re-issue edn, Cambridge University Press, New York, USA, pp. 100116.

14. Chrea, C., Valentin, D., Sulmont-Rossé, C., Nguyen, D.H. \& Abdi, H. 2005, "Semantic, typicality and odor representation: A cross-cultural study", Chemical Senses, vol. 30, no. 1, pp. 37-49.

15. Chrea, C., Valentin, D., Sulmont-Rossé, C., Ly Mai, H., Hoang Nguyen, D. \& Abdi, H. 2004, "Culture and odor categorization: Agreement between cultures depends upon the odors", Food Quality and Preference, vol. 15, no. 7-8 SPEC.ISS., pp. 669-679.

16. Dalton, P. 2000, "Psychophysical and behavioral characteristics of olfactory adaptation", Chemical Senses, vol. 25, no. 4, pp. 487-492.

17. Davide, F., Holmberg, M. \& Lundström, I. 2001, "Virtual olfactory interfaces: Electronic noses and olfactory displays", Communications Through Virtual Technologies: Identity Community and Technology in the Internet Age, pp. 193-220.

18. Dinh, H.Q., Walker, N., Hodges, L.F., Song, C. \& Kobayashi, A. 1999, "Evaluating the importance of multi-sensory input on memory and the sense of presence in virtual environments", Proceedings - Virtual Reality Annual International Symposium, pp. 222228.

19. Djordjevic, J., Zatorre, R.J., Petrides, M. \& Jones-Gotman, M. 2004, "The Mind's Nose: Effects of Odor and Visual Imagery on Odor Detection", Psychological Science, vol. 15, no. 3, pp. 143-148.

20. Doty, R.L., Shaman, P. \& Applebaum, S.L. 1984, "Smell Identification Ability: Changes with Age", Science, vol. 226, no. 4681, pp. 1441-1443.

21. Dubois, D. \& Rouby, C. 2002, "Names and Categories for Odors: The Veridical Label" in Olfaction, Taste, and Cognition, eds. C. Rouby, B. Schaal, D. Dubois, R. Gervais \& A. Holley, Paperback Re-issue edn, Cambridge University Press, New York, USA, pp. 47-66. 
22. Elsner, R.J.F. 2001, "Odor Threshold, Recognition, Discrimination and Identification in Centenarians", Archives of Gerontology and Geriatrics, vol. 33, no. 1, pp. 81-94.

23. Fox, K., 2007, The Smell Report - The human sense of smell, Social Issues Research Centre (SIRC). Available: http://www.sirc.org/publik/smell_human.html [Accessed: November 06, 2007].

24. Frank, R.A., Dulay, M.F., Niergarth, K.A. \& Gesteland, R.C. 2004, "A comparison of the sniff magnitude test and the University of Pennsylvania Smell Identification Test in children and nonnative English speakers", Physiology and Behavior, vol. 81, no. 3, pp. 475-480.

25. Gardiner, M.B. Fall 2004, "A Discerning Obsession. The study of smell brings two HHMI investigators the Nobel Prize", HHMI Bulletin, vol. 17, no. 3, pp. 4 - 6. Available: http://www.hhmi.org/bulletin/fall2004/nobel/. [Accessed: November 16, 2007].

26. Gottfried, J.A. \& Dolan, R.J. 2003, "The nose smells what the eye sees: Crossmodal visual facilitation of human olfactory perception", Neuron, vol. 39, no. 2, pp. 375-386.

27. Gulliver, S.R. 2004, Distributed Multimedia Quality: The User Perspective, Doctor of Philosophy edn, Brunel University, United Kingdom.

28. Gulliver, S.R. \& Ghinea, G. 2006, "Defining user perception of distributed multimedia quality", ACM Transactions on Multimedia Computing, Communications and Applications, vol. 2, no. 4, pp. 241-257.

29. Harel, D., Carmel, L. \& Lancet, D. 2003, "Towards an odor communication system", Computational Biology and Chemistry, vol. 27, no. 2, pp. 121-133.

30. Harel, D., Carmel, L. \& Lancet, D. 2001, An Algorithmic Approach to Odor Communication and Reproduction, Weizmann Science Press of Israel, Jerusalem, Israel, Israel.

31. Herz, R.S. 2002, "Influences of Odors on Mood and Affective Cognition" in Olfaction, Taste, and Cognition, eds. C. Rouby, B. Schaal, D. Dubois, R. Gervais \& A. Holley, Paperback Re-issue edn, Cambridge University Press, New York, USA, pp. 160-177.

32. Hudson, R. \& Distel, H. 2002, "The Individuality of Odor Perception" in Olfaction, Taste, and Cognition, eds. C. Rouby, B. Schaal, D. Dubois, R. Gervais \& A. Holley, Paperback Re-issue edn, Cambridge University Press, New York, USA, pp. 408-420.

33. Hummel, T., Gollisch, R., Wildt, G. \& Kobal, G. 1991, "Changes in olfactory perception during the menstrual cycle", Cellular and Molecular Life Sciences (CMLS), vol. 47, no. 7, pp. 712-715. 
34. Hummel, T., Heilmann, S. \& Murphy, C. 2002, "Age-related Changes in Chemosensory Functions" in Olfaction, Taste, and Cognition, eds. C. Rouby, B. Schaal, D. Dubois, R. Gervais \& A. Holley, Paperback Re-issue edn, Cambridge University Press, New York, USA, pp. 441-456.

35. Hummel, T., Sekinger, B., Wolf, S.R., Pauli, E. \& Kobal, G. 1997, "'Sniffin' sticks'. Olfactory performance assessed by the combined testing of odor identification, odor discrimination and olfactory threshold", Chemical Senses, vol. 22, no. 1, pp. 39-52.

36. Issanchou, S., Valentin, D., Sulmont, C., Degel, J. \& Köster, E.P. 2002, "Testing Odor Memory: Incidental versus Intentional Learning, Implicit versus Explicit Memory" in Olfaction, Taste, and Cognition, eds. C. Rouby, B. Schaal, D. Dubois, R. Gervais \& A. Holley, Paperback Re-issue edn, Cambridge University Press, New York, USA, pp. 211230.

37. Jones, L., Bowers, C.A., Washburn, D., Cortes, A. \& Satya, R.V. 2004, "The Effect of Olfaction on Immersion into Virtual Environments" in Human Performance, Situation Awareness and Automation: Issues and Considerations for the 21st Century Lawrence Erlbaum Associates, pp. 282-285.

38. Kaye, J.J. 2004, "Making Scents: aromatic output for HCI", interactions, vol. 11, no. 1, pp. 48-61.

39. Kaye, J.N. 2001, Symbolic Olfactory Display, Master of Science edn, Massachusetts Institute of Technology, Massachusetts, U.S.A. Available: http://www.media.mit.edu/ jofish/thesis/ [Accessed: September 11, 2005].

40. Keller, A. \& Vosshall, L.B. 2004, "Human Olfactory Psychophysics", Current Biology, vol. 14, no. 20, pp. R875-R878.

41. Kim, D.W., Nishimoto, K., Kunifuji, S. 2006, "An editing and displaying system of olfactory information for the home video", Lecture Notes in Computer Science (including subseries Lecture Notes in Artificial Intelligence and Lecture Notes in Bioinformatics), 4253 LNAI - III, pp. 859-866.

42. Köster, E.P. 2002, "The Specific Characteristics of the Sense of Smell" in Olfaction, Taste, and Cognition, eds. C. Rouby, B. Schaal, D. Dubois, R. Gervais \& A. Holley, Paperback Re-issue edn, Cambridge University Press, New York, USA, pp. 27-44. 
43. Laing, D.G. 1983, "Natural sniffing gives optimum odour perception for humans", Perception, vol. 12, no. 2, pp. 99-117.

44. Larsson, M. 2002, "Odor Memory: A Memory Systems Approach" in Olfaction, Taste, and Cognition, eds. C. Rouby, B. Schaal, D. Dubois, R. Gervais \& A. Holley, Paperback Re-issue edn, Cambridge University Press, New York, USA, pp. 231-245.

45. Larsson, M., Finkel, D. \& Pedersen, N.L. 2000, "Odor Identification: Influences of Age, Gender, Cognition, and Personality", Journals of Gerontology - Series B Psychological Sciences and Social Sciences, vol. 55, no. 5, pp. P304-P310.

46. Lehrner, J. \& Walla, P. 2002, "Development of Odor Naming and Odor Memory from Childhood to Young Adulthood" in Olfaction, Taste, and Cognition, eds. C. Rouby, B. Schaal, D. Dubois, R. Gervais \& A. Holley, Paperback Re-issue edn, Cambridge University Press, New York, USA, pp. 278-290.

47. Lundström, J.N., McClintock, M.K. \& Olsson, M.J. 2006, "Effects of reproductive state on olfactory sensitivity suggest odor specificity", Biological Psychology, vol. 71, no. 3, pp. 244-247.

48. Mair, R.G., Bouffard, J.A., Engen, T. \& Morton, T.H. 1978, "Olfactory sensitivity during the menstrual cycle", Sensory Processes, vol. 2, no. 2, pp. 90-98.

49. Matsukura, H., Yoshida, H., Ishida, H., Nakamoto, T. 2009, "Interactive Odor Playback Based on Fluid Dynamics Simulation", VR 2009 - IEEE Virtual Reality Conference, art. no. 4811042, pp. 255-256, Lafayette, Louisiana, USA.

50. Matsukura, H., Yoshida, H., Ishida, H., Saitoh, A., Nakamoto, T. 2009, "Odor Presentation with a Vivid Sense of Reality: Incorporating Fluid Dynamics Simulation into Olfactory Display", VR 2009 - IEEE Virtual Reality Conference, art. no. 4811062, pp. 295-296, Lafayette, Louisiana, USA.

51. Mizuno, K. \& Ueda, A. 2004, "Antenatal olfactory learning influences infant feeding", Early Human Development, vol. 76, no. 2, pp. 83-90.

52. Mochizuki, A., Amada, T., Sawa, S., Takeda, T., Motoyashiki, S., Kohyama, K., Imura, M. \& Chihara, K. 2004, "Fragra: a visual-olfactory VR game", SIGGRAPH '04: ACM SIGGRAPH 2004 SketchesACM Press, New York, NY, USA, pp. 123.

53. Morrot, G., Brochet, F. \& Dubourdieu, D. 2001, "The Color of Odors", Brain and Language, vol. 79, no. 2, pp. 309-320. 
54. Moskowitz, H.R., Dravnieks, A., Cain, W.S. \& Turk, A. 1974, "Standardized procedure for expressing odor intensity", CHEM.SENSES FLAVOR, vol. 1, no. 2, pp. 235-237.

55. Nagle, H.T., Schiffman, S.S. \& Gutierrez-Osuna, R. 1998, "How and why of electronic noses", IEEE Spectrum, vol. 35, no. 9, pp. 22-34.

56. Nakaizumi, F., Yanagida, Y., Noma, H., Hosaka, K. 2006, "SpotScents: A novel method of natural scent delivery using multiple scent projectors", VR'06 - IEEE Virtual Reality Conference 2006, art. no. 1624066, pp. 207 - 214, Alexandria, Virginia, USA.

57. Nakamoto, T., Murakami, K. 2009, "Selection method of odor components for olfactory display using mass spectrum database", VR 2009 - IEEE Virtual Reality Conference 2009, art. no. 4811016, pp. 159-162, Lafayette, LA, USA.

58. Nakamoto, T., Otaguro, S., Kinoshita, M., Nagahama, M., Ohinishi, K., Ishida, T. 2008. "Cooking up an Interactive Olfactory Game Display", IEEE Computer Graphics and Applications, 28(1), pp.75-78.

59. Nakamoto, T. 2006. "Movie with Scents Generated by Olfactory Display Using Solenoid Valves", IEICE Transactions on Fundamentals of Electronics, Communications and Computer Sciences, E89-A (11), pp. 3327-3332.

60. Nakamoto, T. 2005, "Odor recorder", Sensor Letters, vol. 3, no. 2, pp. 136-150.

61. Nakamoto, T. 2005, "Record of dynamic changes of odors using an odor recorder", Sensors and Materials, vol. 17, no. 7, pp. 365-383.

62. Öberg, C., Larsson, M. \& Bäckman, L. 2002, "Differential Sex Effects in Olfactory Functioning: The role of verbal processing", Journal of the International Neuropsychological Society, vol. 8, no. 5, pp. 691-698.

63. Olofsson, J.K. \& Nordin, S. 2004, "Gender differences in chemosensory perception and event-related potentials", Chemical Senses, vol. 29, no. 7, pp. 629-637.

64. Parr, W.V., Heatherbell, D. \& White, K.G. 2002, "Demystifying wine expertise: Olfactory threshold, perceptual skill and semantic memory in expert and novice wine judges", Chemical Senses, vol. 27, no. 8, pp. 747-755.

65. Parr, W.V., White, K.G. \& Heatherbell, D.A. 2004, "Exploring the nature of wine expertise: What underlies wine experts' olfactory recognition memory advantage?", Food Quality and Preference, vol. 15, no. 5, pp. 411-420. 
66. Pines, M., The Mystery of Smell: The Vivid World of Odors, Howard Hughes Medical Institute (HHMI). Available: http://www.hhmi.org/senses/d110.html [Accessed: November 16, 2007].

67. Pornpanomchai, C., Threekhunprapa, A., Pongrasamiroj, K., Sukklay, P. 2009, "SubSmell: Multimedia with a simple olfactory display", Lecture Notes in Computer Science (including subseries Lecture Notes in Artificial Intelligence and Lecture Notes in Bioinformatics), 5414 LNCS, pp. 462-472.

68. Rowe, L.A. \& Jain, R. 2005, "ACM SIGMM retreat report on future directions in multimedia research", ACM Transactions on Multimedia Computing, Communications, and Applications, vol. 1, no. 1, pp. 3-13.

69. Sakai, N., Imada, S., Saito, S., Kobayakawa, T. \& Deguchi, Y. 2005, "The effect of visual images on perception of odors", Chemical Senses, vol. 30 SUPPL. 1.

70. Saito, S., Ayabe-Kanamura, S., Takashima, Y., Gotow, N., Naito, N., Nozawa, T., Mise, M., Deguchi, Y. \& Kobayakawa, T. 2006, "Development of a smell identification test using a novel stick-type odor presentation kit", Chemical Senses, vol. 31, no. 4, pp. 379391.

71. Saltus, R., 2007, "Common Senses", HHMI Bulletin, vol. 20, no. 1, pp. 3. Available: http://www.hhmi.org/bulletin/feb2007/features/senses3.html. [Accessed: November 16, 2007].

72. Sarter, N.B. 2006, "Multimodal information presentation: Design guidance and research challenges", International Journal of Industrial Ergonomics, vol. 36, no. 5, pp. 439-445.

73. Schaal, B., Montagner, H., Hertling, E., Bolzoni, D., Moyse, A. \& Quichon, R. 1980, "Olfactory Stimulation in the Relationship between Child and Mother", Reproduction, Nutrition, Development, vol. 20, no. 3B, pp. 843-858.

74. Schaal, B., Soussignan, R. \& Marlier, L. 2002, "Olfactory Cognition at the Start of Life: The Perinatal Shaping of Selective Odor Responsiveness" in Olfaction, Taste, and Cognition, eds. C. Rouby, B. Schaal, D. Dubois, R. Gervais \& A. Holley, Paperback Reissue edn, Cambridge University Press, New York, USA, pp. 421-440.

75. Spencer, B.S. 2006, "Incorporating the Sense of Smell Into Patient and Haptic Surgical Simulators", IEEE Transactions on Information Technology in Biomedicine, vol. 10, no. 1, pp. $168-173$. 
76. Stevenson, R.J. \& Case, T.I. 2005, "Olfactory imagery: A review", Psychonomic Bulletin and Review, vol. 12, no. 2, pp. 244-264.

77. Stevenson, R.J., Mahmut, M. \& Sundqvist, N. 2007, "Age-Related Changes in Odor Discrimination", Developmental Psychology, vol. 43, no. 1, pp. 253-260.

78. Todrank, J., Wysock, C.J. \& Beauchamp, G.K. 1991, "The effects of adaptation on the perception of similar and dissimilar odors", Chemical Senses, vol. 16, no. 5, pp. 467-482.

79. Toledano, A. 2004, "Is the CCCRC olfactory test a universal test?", Otolaryngology Head and Neck Surgery, vol. 131, no. 2, pp. P55.

80. Tortell, R., Luigi, D.P., Dozois, A., Bouchard, S., Morie, J.F. \& Ilan, D. 2007, "The effects of scent and game play experience on memory of a virtual environment", Virtual Reality.

81. Varendi, H., Porter, R.H. \& Winberg, J. 1997, "Natural odour preferences of newborn infants change over time", Acta Paediatrica, International Journal of Paediatrics, vol. 86, no. 9, pp. 985-990.

82. Variety staff 2001, Variety review of "Scent of Mystery", Variety, Inc., Available: 82 [Accessed: August 21, 2007].

83. Ward, P., Davies, B. \& Kooijman, D. 2007, "Olfaction and the retail environment: examining the influence of ambient scent", Service Business, vol. 1, no. 4, pp. 295-316.

84. Washburn, D.A., Jones, L.M., Satya, R.V., Bowers, C.A. \& Cortes, A. , Olfactory Use in Virtual Environment Training, Modelling and Simulation Magazine, Institute for Simulation and Training, University of Central Florida, vol. 2, no. 3. Available: http://www.modelingandsimulation.org/issue7/olfactory.html [Accessed: November 17, 2007].

85. Washburn, D.A. \& Jones, L.M. 2004, "Could Olfactory Displays Improve Data Visualization?", Computing in Science and Engg., vol. 6, no. 6, pp. 80-83.

86. Watanabe, K., Umezu, K. \& Kurahashi, T. 2002, "Human olfactory contrast changes during the menstrual cycle", Japanese Journal of Physiology, vol. 52, no. 4, pp. 353-359.

87. Yanagida, Y., Noma, H., Tetsutani, N. \& Tomono, A. 2003, "An unencumbering, localized olfactory display", CHI '03: CHI '03 extended abstracts on Human factors in computing systems ACM, New York, NY, USA, pp. 988. 
88. Yanagida, Y., Kawato, S., Noma, H., Tetsutani, N., and Tomono, A. 2003. "A nosetracked, personal olfactory display", ACM SIGGRAPH 2003 Sketches \& Applications, pp. 1-1, San Diego, California, USA. 


\section{Web References}

89. $6423=A$ Rose, 1943, Time. Available:

http://www.time.com/time/magazine/article/0,9171,851882,00.html [Accessed: November $16,2007]$.

90. Aging Well with Your Sense of Smell: a handbook for baby boomers, Olfactory Research Fund, Ltd. Available: http://www.senseofsmell.org/pdf/AgingWell.pdf [Accessed: November 16, 2007]

91. Carl

Linnaeus

(1707-1778).

Available: http://www.ucmp.berkeley.edu/history/linnaeus.html [Accessed: November 16, 2007].

92. Fragra - An Interactive Olfactory Game System, 2003, IVRC (Inter-collegiate Virtual Reality Contest) $\quad$ www.ivrc.net. $\quad$ Available: $\underline{\text { http://chihara.aist- }}$ nara.ac.jp/ivrc2003/index.html [Accessed: August 23, 2007].

93. Flavour Wheel for Maple Products, Agriculture and Agri-Food Canada. Available: http://www.agr.gc.ca/maple_wheel/index_e.php?page=wheel-roue [Accessed: November $16,2007]$.

94. Flavor

Wheels

of the World, 2004.

Available: http://www.eblong.com/zarf/flavorwheel.html [Accessed: November 16, 2007].

95. Flavour

Wheel.

Available: http://www.oxfordchemicals.com/oxford/ocweb.nsf/flavourwheel!OpenPage [Accessed: November 16, 2007]

96. Fragrances of the World. Available: http://www.fragrancesoftheworld.com/fotw_home.swf [Accessed: November 16, 2007].

97. Olfactory Types, 1996, Available: http://sun.science.wayne.edu/ wpoff/cor/sen/smeltype.html [Accessed: November 16, 2007].

98. The Scent Collar, The Institute for Creative Technologies \& AnthroTronix, Inc. Available: http://people.ict.usc.edu/ morie/ScentCollarBrochure.pdf [Accessed: November 17, 2007].

99. Sensorama's Pre-Virtual Reality, Eric Lefcowitz. Available: http://www.retrofuture.com/sensorama.html [Accessed: August 23, 2007].

100. ABC News 1999, Smell-O-Vision Coming to Internet Soon. Available: http://www.temple.edu/ispr/examples/ex99_10_20.html [Accessed: August 21, 2007]. 
101. Artmuseum.net, Morton Heilig | Sensorama <1962>, Artmuseum.net. Available: http://www.artmuseum.net/w2vr/timeline/Heilig.html [Accessed: August 23, 2007].

102. BBC 2006, 'Smellovision' for Japan cinema, BBC. Available: http://news.bbc.co.uk/1/hi/entertainment/4903984.stm [Accessed: August 21, 2007].

103. Christensen, B. 2006, The Real ICT Scent Collar, Technovelgy.com. Available: http://www.technovelgy.com/ct/Science-Fiction-News.asp?NewsNum=529 [Accessed: November 17, 2007].

104. Colman, A.M., 2001, Crocker-Henderson system. Available: http://www.encyclopedia.com/doc/1087-CrockerHendersonsystem.html [Accessed: November 16, 2007].

105. Colman, A.M., 2001, Henning's prism. Available: http://www.encyclopedia.com/doc/1087-Henningsprism.html [Accessed: November 16, 2007].

106. Colman, A.M., 2001, Zwaardemaker smell system. Available:

http://www.encyclopedia.com/doc/1087-Zwaardemakersmellsystem.html [Accessed:

November 16, 2007].

107. Dictionary.com, Odour, Dictionary.com Unabridged (v 1.1). Random House, Inc.]. Available: http://dictionary.reference.com/browse/odour [Accessed: November 16, 2007].

108. Heritage, S. 2006, The New Colin Farrell Movie Stinks In Japan. Available: http://www.hecklerspray.com/the-new-colin-farrell-movie-stinks-in-japan/20062756.php [Accessed: August 23, 2007].

109. HHMI News, 2001, Researchers Discover Precise Olfactory Map. Available: http://www.hhmi.org/news/buck3.html [Accessed: November 16, 2007].

110. Jacob, T., A tutorial on the sense of smell, Cardiff University, UK. Available: http://www.cf.ac.uk/biosi/staff/jacob/teaching/sensory/olfact1.html [Accessed: November $16,2007]$.

111. Kiger, P.J. \& Smith, M.J. 2006, Lesson \#9 - Beware of Unproven Technologies The Lingering Reek of "Smell-O-Vision", HarperCollins. Available: http://www.in70mm.com/news/2006/oops/index.htm [Accessed: August 21, 2007].

112. Leffingwell, J.C., Olfaction. Available: http://www.leffingwell.com/olfaction.htm [Accessed: September 21, 2007]. 
113. Mautner, J. 2006 Making dollars from Scents, Available: http://www.foodarts.com/Foodarts/FA_Feature/0,4041,129,00.html [Accessed: February $15,2010]$.

114. Nakamoto, T., Cooking game with scents, Tokyo Institute of Technology. Available: http://www.titech.ac.jp/news/e/news061129.html [Accessed: August 23, 2007].

115. Nakamoto, T., Cooking game with scents, Nakamoto Lab, Tokyo Institute of Technology]. Available: http://silvia.mn.ee.titech.ac.jp/research/cookingcontents.htm [Accessed: August 24, 2007].

116. Nobelprize.org, 2004, The Nobel Prize in Physiology or Medicine 2004. Available: http://nobelprize.org/nobel_prizes/medicine/laureates/2004/press.html [Accessed: November 16, 2007].

117. NTT Communications (NTT Com) 2006, Movie Enhanced with Internet-based Fragrance System. Available: http://www.in70mm.com/news/2006/new_world/index.htm [Accessed: August 21, 2007].

118. Osborne, G., 2001, Interview with Michael Edwards, Basenotes. Available: http://www.basenotes.net/interviews/int-medwards.html [Accessed: November 16, 2007].

119. Platt, C. 1999, You've Got Smell!, Wired Magazine, vol. 7, no. 11. Available: http://www.wired.com/wired/archive/7.11/digiscent.html [Accessed: November 17, 2007].

120. Smith, M.J. \& Kiger, P.J. 2006, The Lingering Reek of Smell-O-Vision, Los Angeles Times. Available: $\quad$ http://www.latimes.com/features/magazine/west/la-tmoops6feb05,1,2932206.story?coll=la-iraq-complete [Accessed: August 21, 2007].

121. Vafai, S., Does olfactory acuity decline with age? Available: http://zebra.sc.edu/smell/ann/myth2.html [Accessed: November 17, 2007].

122. Vafai, S., Do men and women differ in their capacity to detect odors?. Available: http://zebra.sc.edu/smell/ann/myth1.html [Accessed: November 17, 2007].

123. Well\&Good 2004 Issue 4, Sense of smell, University of Iowa Health Care, Available: http://www.uihealthcare.com/news/wellandgood/2004/issue4/senseofsmell.html [Accessed: November 06, 2007]. 
